\title{
COMMENTARX
}

\section{Healthier on arrival? Further insight into the "healthy immigrant effect"}

\section{Brian Gushulak}

$\infty \quad$ See related article page I4I9

I $\mathrm{n}$ this issue Ray and colleagues ${ }^{1}$ explore the relation between immigration to Canada (Ontario specifically) and the risk of placental dysfunction. Quantifying a triad of obstetric complications (pre-eclampsia or eclampsia, placental abruption and placental infarction), the study team observed that the risk of these outcomes increased in a cohort of women the longer it had been since their arrival in Ontario. This pattern whereby newcomers initially present positive health characteristics that deteriorate or worsen following immigration is known as the "healthy immigrant effect." Better understanding of the dynamics of evolving health characteristics in immigrants is increasingly important given the demographic impact of immigration in Canada and other countries receiving immigrants.

Studies such as the one by Ray and colleagues ${ }^{1}$ raise issues related to maintaining the health of immigrants and have implications that extend across social and biomedical boundaries. The medical consequences of immigration, both perceived and real, significantly influence public health and immigration policies and practice. Examining the health effects of migration is most frequently undertaken in $\mathrm{I}$ of 3 ways. ${ }^{2}$ Studies may compare characteristics or outcomes in a cohort of immigrants with those in a demographically similar component of the host population. Alternatively, as undertaken in the study by Ray and colleagues, a population of immigrants may be followed to delineate changes in health outcomes or characteristics over time. Lastly, and rarely, the effects of migration may be observed by comparing a group of immigrants with nonimmigrant counterparts who remained at their place of origin.

Much of the historical focus on health and migration has compared characteristics between immigrants and the host population. Traditionally, this approach centred on managing the threat or risks of migrant-imported infectious diseases, such as plague, cholera and tuberculosis. The understandable fear of epidemic disease arriving with foreigners was augmented early in the last century by social and political n perceptions about the perceived risks of behavioural disorders, chronic diseases and noninfectious conditions that were claimed to be more common in some immigrant groups. Those perceptions influenced the medical approach to new immigrants and continue to be reflected in immigration policy and practices of some major immigrant-receiving countries. ${ }^{3}$ This approach is fundamentally based on the medical evaluation and screening of immigrants with the intent of identifying those with diseases or conditions and preventing their admission.

As Ray and colleagues note in their discussion, immigration legislation in Canada and other nations requires applicants to undergo medical examination to determine whether they are healthy enough to be admitted. This practice maintains a situation where considerable focus and effort on immigrant health is centred on admission screening, which is limited to the time of immigration processing and the immediate period of arrival. The health determinants and influences affecting immigrants before their arrival, during the transit period itself and in the long term after arrival have received less attention and policy consideration.

\section{The medical consequences} of immigration, both perceived and real, influence public health and immigration policies and practice.

The attention devoted to the identification and management of immigrants arriving with pre-existing diseases has been supported in relation to some infectious diseases for which the prevalence in the nations of origin greatly exceeds that observed in the destination country. Tuberculosis is a classic example. However, in Australia, western Europe, ${ }^{4}$ the United States ${ }^{5}$ and Canada, ${ }^{6}$ it has been observed that several immigrant populations initially display health characteristics that are equal to or better than those of the host population. These positive factors can be seen in the incidence and outcomes of several chronic diseases and conditions as well as in the utilization of health care services by new immigrants following their arrival in developed high-income nations. ${ }^{7}$ In addition, recent immigrants have been found to have a higher self-perception of better health than matched groups in the host population and to use health care services less often than their domestic counterparts. ${ }^{8}$ 
Traditionally, the healthy immigrant effect is believed to be a consequence of several health and social factors. ${ }^{9}$ Many immigrants originate from regions of the world where lifestyle-associated behaviours contributing to chronic diseases, particularly those associated with obesity, inactivity and diet, are less prevalent than those observed in the developed world. Second, nations that have complex immigration selection processes often search for younger and better educated immigrants, who may also be better able than older, less healthy immigrants to cope successfully with the physical, psychological and sociological challenges of immigration. Finally, it has been suggested that immigration medical requirements and screening for chronic diseases may deny admission to individuals with existing illness or support selfselection of healthier individuals.

The deterioration of some positive health characteristics soon after arrival in the destination country to levels that are similar to those in the host population is likewise believed to result from a combination of behavioural and environmental changes. There is evidence that the process of acculturalization is associated with changes in diet and activity level and use of medical services in some immigrants. Increased body mass index, altered glucose metabolism and behavioural changes (e.g., use of tobacco, alcohol or other substances) following arrival may increase the risk of adverse health outcomes..$^{10}$ Some of these factors are known to affect maternal and child health.

However, Ray and colleagues present information that suggests that other factors may be influencing the obstetric outcomes in the immigrant population in Ontario sooner than has been observed in other examples of the healthy immigrant effect. Although this may be related to the acquisition of risk factors in Canada, it may also be related to the loss of protective factors associated with leaving the country of origin. These findings clearly warrant further consideration and elaboration. The study also adds to the existing evidence of the complex relations between pregnancy outcomes and the process of immigration itself. Recent studies involving mobile populations in the United States, for example, have suggested that improved birth outcomes in migrant populations extended to mothers who not only migrated internationally but also moved between regions within that country. ${ }^{11}$ Given the importance of reducing the risk of obstetric complications, more detailed investigation is warranted.

In addition to addressing some of the gaps in knowledge noted by Ray and colleagues, ${ }^{1}$ research will need to address issues related to study design. Foreign-born immigrants represent a collection of diverse and often disparate populations and experiences. The factors affecting the health outcomes of particularly vulnerable groups and cohorts (e.g., refugees and refugee claimants) will need to be quantified, as will the influences related to ethnicity and geographic origin. The impact of national and provincial policies that determine access to health care services also warrants attention.

From a policy perspective, the study by Ray and colleagues and other investigations examining the longer-term health implications of immigration are important for 3 reasons. They support nascent efforts to expand the scope and focus of traditional immigration health away from screening for exclusion toward an integrated approach that sustains and improves the health of immigrants. ${ }^{12}$ Second, studies that describe and quantify the healthy immigrant effect reduce some of the erroneous impressions that immigrants frequently require or consume excessive amounts of medical services. Finally, and perhaps most importantly, these studies provide information that will generate better tools and interventions to maintain the health of those representing the largest component of Canada's population growth.

For the past 2 decades Brian Gushulak has focused on international health and immigration both in Canada and abroad. He has held positions in the federal health and immigration departments and has worked in the international sector as the Director of Migration Health Services at the International Organization for Migration, Geneva. He is now engaged in research and consulting in the area of health and population mobility.

Competing interests: None declared.

\section{REFERENCES}

I. Ray JG, Vermeulen MJ, Schull MJ, et al. Results of the Recent Immigrant Pregnancy and Perinatal Long-term Evaluation Study (RIPPLES). CMAJ 2007;I76(I0):I4I9-26.

2. McKay L, Macintyre S, Ellaway A. Migration and health: a review of the international literature [Occasional Paper no I2]. Glasgow: Medical Research Council, Social and Public Health Sciences Unit; 2003. Available: www.msoc-mrc.gla.ac.uk Ifiles/File/library/occasional/OPoI2.pdf (accessed 2007 Apr 2).

3. Gushulak BD, MacPherson WD. Migration medicine and health: principles and practice. Hamilton (ON): BC Decker; 2006.

4. Yoong W, Wagley A, Fong C, et al. Obstetric performance of ethnic Kosovo Albanian asylum seekers in London: a case-control study. JObstet Gynaecol 2004;24:510-2.

5. Antecol H, Bedard $\mathrm{K}$. Unhealthy assimilation: why do immigrants converge to American health status levels? Demography 2006;43:337-6o.

6. Hyman I. Immigration and health [Health Policy Working Paper Series, working paper no or-05]. Ottawa: Health Canada; 200I. Available: www.hc-sc.gc.ca/sr-sr/pubs /hpr-rpms/wp-dt/200I-oI05-immigration/index_e.html (accessed 2007 Apr 2).

7. Singh GK, Siahpush M. Ethnic-immigrant differentials in health behaviors, morbidity, and cause-specific mortality in the United States: an analysis of two national data bases. Hum Biol 2002;74:83-Io9.

8. Baron-Epel O, Kaplan G. Self-reported health status of immigrants from the former Soviet Union in Israel. Isr Med Assoc J 200I;3:940-6.

9. Oxman-Martinez J, Abdool S, Loiselle-Léonard M. Immigration, women and health in Canada. Can J Public Health 2000;91:394-5.

Io. Mazur RE, Marquis GS, Jensen HH. Diet and food insufficiency among Hispanic youths: acculturation and socioeconomic factors in the third National Health and Nutrition Examination Survey. Am J Clin Nutr 2003;78:1120-7.

II. Wingate MS, Alexander GR. The healthy migrant theory: variations in pregnancy outcomes among US-born migrants. Soc Sci Med 2006;62:49I-8.

I2. Maloney S. Migration health policies: shifting the paradigm from exclusion to inclusion. In: IOM's International Dialogue on Migration. Seminar on Health and Migration; 2004 June 9-II. Geneva: International Organization for Migration. Available: www.iom.int/jahia/webdav/site/myjahiasite/shared/shared/mainsite/microsites/IDM /workshops/Health_and_Migration_09110604/se3_conf_natmigration.pdf (accessed 2007 Apr 2).

Correspondence to: Dr. Brian Gushulak, Migration Health

Consultants Inc., I4I30 Creditview Rd., Cheltenham $\mathrm{ON} \mathrm{L}_{7} \mathrm{C}_{\mathrm{I}_{4}}$; brian.gushulak@aon.at 